\title{
Thrust stand for vertically oriented electric propulsion performance evaluation
}

\author{
Trevor Moeller* \\ University of Tennessee Space Institute, Tullahoma, TN 37388 \\ Kurt A. Polzin ${ }^{\dagger}$ \\ NASA-Marshall Space Flight Center, Huntsville, AL 35812
}

\begin{abstract}
A variation of a hanging pendulum thrust stand capable of measuring the performance of an electric thruster operating in the vertical orientation is presented. The vertical orientation of the thruster dictates that the thruster must be horizontally offset from the pendulum pivot arm, necessitating the use of a counterweight system to provide a neutrally-stable system. Motion of the pendulum arm is transferred through a balance mechanism to a secondary arm on which deflection is measured. A non-contact light-based transducer is used to measure displacement of the secondary beam. The members experience very little friction, rotating on twisting torsional pivots with oscillatory motion attenuated by a passive, eddy current damper. Displacement is calibrated using an in situ thrust calibration system. Thermal management and self-leveling systems are incorporated to mitigate thermal and mechanical drifts. Gravitational restoring force and torsional spring constants associated with flexure pivots provide restoring moments. An analysis of the design indicates that the thrust measurement range spans roughly four decades, with the stand capable of measuring thrust up to 12 $\mathrm{N}$ for a $200 \mathrm{~kg}$ thruster and up to approximately $800 \mathrm{mN}$ for a $10 \mathrm{~kg}$ thruster. Data obtained from calibration tests performed using a $26.8 \mathrm{lbm}$ simulated thruster indicated a resolution of $1 \mathrm{mN}$ on $100 \mathrm{mN}$-level thrusts, while those tests conducted on $200 \mathrm{lbm}$ thruster yielded a resolution of roughly $2.5 \mathrm{mN}$ at thrust levels of $0.5 \mathrm{~N}$ and greater.
\end{abstract}

\section{Introduction}

$\mathrm{T}$ HE evaluation of the performance of any propulsion requires the accurate measurement of thrust. While chemical rocket thrust is typically measured using a load cell, ${ }^{1}$ the low thrust levels associated with electric propulsion (EP) systems necessitate the use of much more sensitive measurement techniques. Historically, thrust stands for EP systems can be sorted into two categories: null thrust stands where the thruster is held in the same position and thrust stands that measure thrust through the displacement of a member. Null thrust stands utilize technologies for measuring small forces, such as crystal microbalances, to obtain a direct measure of thrust. ${ }^{2,3}$ Stands that rely on the displacement of a member are far more prevalent ${ }^{4,5}$ and can typically be further classified as either a hanging pendulum, inverted pendulum, or torsional pendulum design.

The hanging pendulum design is the most simple, with the gravitational restoring force yielding a configuration that is extremely stable when perturbed by external forces. However, such stability comes at the cost of sensitivity. Sensitivity can be regained by increasing the length of the pendulum arm, but this may be impractical in smaller test facilities (vacuum chambers). Consequently, the hanging pendulum has typically been used to perform measurements on thrusters possessing high thrust-to-weight, T/W, ratios ${ }^{6,7}$ (e.g. magnetoplasmadynamic (MPD) thrusters ${ }^{8-10}$ ). Recently, a variant of the hanging pendulum thrust stand, possessing a pendulum arm connecting through a series of torsional pivots to a secondary arm, was developed and tested. ${ }^{4}$ This design maintains the stability of a hanging pendulum thrust stand, but has demonstrated increased sensitivity in performing thrust measurements on low-power Hall thrusters down to the mN-level.

Inverted pendulum thrust stands are less stable but more sensitive than the traditional hanging pendulum design. ${ }^{4,11}$ They have been widely used to measure the performance of EP devices over a wide range of thrust-to-weight ratios; for

\footnotetext{
*Assistant Professor, Department of Mechanical, Aerospace, and Biomedical Engineering, 411 B.H. Goethert Parkway. Associate Fellow AIAA

${ }^{\dagger}$ Propulsion Research Engineer, Propulsion Research and Technology Applications Branch, Propulsion Systems Department. Senior Member AIAA.
} 
example resistojets, electrothermal arcjets, MPD thrusters, Hall thrusters, ${ }^{12-14}$ and ion engines. The higher sensitivity of the inverted pendulum configuration is obtained through a trade-off with thrust stand stability. This stability is a function of the stiffness of the supporting flexures, which can change of the course of a test due to, among other factors, heating.

The displacement member in the torsional thrust stand configuration rotates about an axis parallel to the gravity vector. This configuration can be designed so that the restoring force is independent of the thruster mass (unlike the hanging or inverted pendulum). Consequently, torsional pendulum thrust stands possess the highest sensitivity of any of the thrust stand configurations. ${ }^{15-21}$ Torsional thrust stands have been recently used in the evaluation of microthruster performance, ${ }^{5,22-24}$ and they have been effective in measuring the performance of pulsed thrusters.

In general, present thrust stands for EP are designed for use in vacuum facilities where the thrust axis is aligned parallel with the horizontal. However, there are vacuum facilities in operation that can only accommodate thrusters operating with the thrust axis oriented in the vertical direction. In the present paper we describe a vertical thrust stand (VTS) for EP thrust measurements that has been adapted from the modified hanging pendulum design discussed in work by Polzin et al. ${ }^{4}$ The commonalities and differences in the two designs are discussed and calibration data are presented to demonstrate the utility of the present design.

\section{Vertical Thrust Stand Design}

The VTS described in this paper has been specifically designed for use in the Arnold Engineering Development Center (AEDC) $12 \mathrm{~V}$ test facility. Like all other displacement-based thrust measurement techniques, the VTS is susceptible to errors introduced by 'zero drift', which means that the displaced member does not return to the initial position when the thruster is turned off. Minor distortions in a vacuum chamber, caused either through mechanical loading during chamber evacuation or thermally-induced expansion and contraction, can cause the thrust stand to deviate from an initially-level position. The VTS incorporates several subsystems to counteract these effects, including active thermal management of the thrust stand platform, in situ leveling capabilities, and real-time monitoring of the level to ensure it remains aligned with Earth's gravity vector. In addition, the thrust stand possesses in situ calibration capabilities, has a passive oscillation damping system, employs nonmetallic thrust stand members near the thruster to eliminate induced currents, and uses liquid metal pots to transfer power from the stationary portion of the thrust stand to the thruster.

\section{A. Balance Mechanism}

A schematic representation of the VTS is shown photographically in Fig. 1 and schematically in Fig. 2. It is a modified version of the Variable Amplitude Hanging Pendulum with Extended Range (VAHPER) thrust stand presently in use at NASA-Marshall Space Flight Center (MSFC). ${ }^{4}$ The VTS consists of a system of linkages whereby motion of the primary member about point $\mathrm{B}$ causes motion of the secondary beam DEF about point $\mathrm{E}$. The two members are coupled through the linkage CD, and the positions of both $\mathrm{C}$ and $\mathrm{D}$ can be adjusted. Unlike the VAHPER design, a counterbalance is attached to the primary beam at $\mathrm{H}$ and is needed in the VTS design to balance the thruster mass and provide a neutral hanging position. The counterbalance consists of plates of various weights that can be attached to the end of the primary beam and allows a rough counterbalancing of the primary beam. An adjustable counterbalance attached to the primary beam is moved along linear guides by a stepper-linear actuator mechanism to provide fine counterbalance adjustments.

Unless otherwise noted, displacements are represented by the vector $\mathbf{d}_{\mathrm{ij}}$, member lengths by $l_{\mathrm{ij}}$, and angles by $\theta_{\mathrm{ijk}}$, where $\mathrm{i}, \mathrm{j}$, and $\mathrm{k}$ are the end points. Application of the thrust $\mathbf{T}$ in the vertical direction at point $\mathrm{G}$ causes the members GABCH and DEF to rotate through angles $\alpha_{1}$ and $\alpha_{2}$. In the small-angle limit, the rotational deflection $\alpha_{1}$ is converted to (amplified) vertical deflection $\mathbf{d}_{\mathrm{FF}^{\prime}}$. Like the VAHPER thrust stand, the two pivots (at $\mathrm{B}$ and $\mathrm{E}$ ) in the VTS are mounted to the same structure as the displacement transducer measuring the deflection at point F, eliminating the need for a separate (and problematic) reference structure. The positions of all the pivots are given in Table 1.

In performing our analysis of the mechanics of the stand, the problem is simplified by assuming that points A, B, $\mathrm{C}$, and $\mathrm{H}$ are colinear, and that points $\mathrm{D}, \mathrm{E}$, and $\mathrm{F}$ are colinear. In addition, we assume that the center of gravity of the counterweight is located at point G. These simplifications are made only to make the mathematics easier to follow and do not dramatically affect the results of the analysis.

The trigonometric exercise relating the displacement of the thruster $\mathbf{d}_{\mathrm{GG}^{\prime}}$ to $\mathbf{d}_{\mathrm{FF}^{\prime}}$ at the location of the displace- 


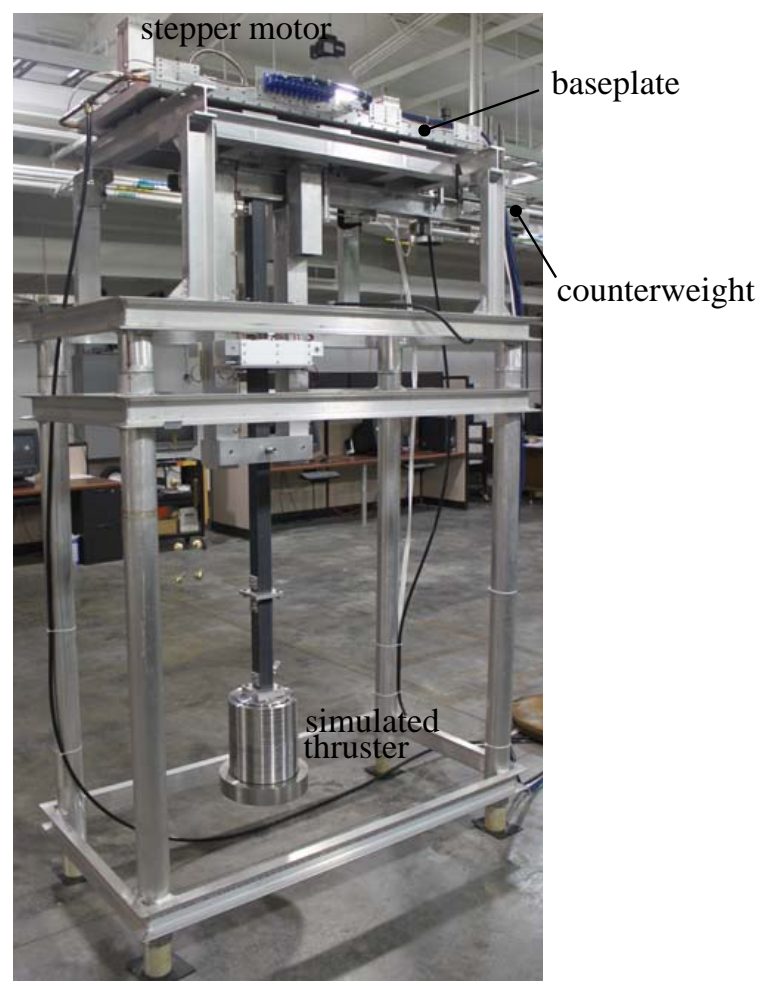

Figure 1. Photograph of the VTS, mounted on a support structure.

ment measurement is performed in section A of the Appendix. The results of this analysis are given as

$$
\begin{aligned}
& \alpha_{1}=2 \sin ^{-1}\left(\frac{\left|\mathbf{d}_{\mathrm{GG}^{\prime}}\right|}{2 l_{\mathrm{GB}}}\right), \quad\left|\mathbf{d}_{\mathrm{FF}^{\prime}}\right|=2 l_{\mathrm{EF}} \sin \left(\frac{\alpha_{2}}{2}\right), \\
& \alpha_{2}=\alpha_{1}+\theta_{\mathrm{BC}^{\prime} \mathrm{D}^{\prime}}+\theta_{\mathrm{C}^{\prime} \mathrm{D}^{\prime} \mathrm{E}}-\theta_{\mathrm{BCD}}-\theta_{\mathrm{CDE}},
\end{aligned}
$$

where all the lengths and angles are known in terms of the initial geometric configuration and are defined in section A of the Appendix.

To find the amount of actual deflection $\left|\mathbf{d}_{\mathrm{FF}^{\prime}}\right|$ realized for a given level of thrust, we must perform a free body analysis of the various members, taking into account the restoring moments exerted by the torsional flextures and the mass of the thruster (located at point A). This analysis is found in section B of the Appendix and results in an expression relating the thrust $|\mathbf{T}|$ to the angle $\alpha_{1}$ :

$$
\begin{aligned}
T & =\left[M_{\mathrm{B}}+M_{\mathrm{C}^{\prime}}+m_{\mathrm{T}} g l_{\mathrm{BG}} \cos \left(\theta_{\mathrm{GBA}}-\alpha_{1}\right)-m_{\mathrm{CW}} g l_{\mathrm{BH}} \cos \alpha_{1}+F_{\mathrm{C}^{\prime} \mathrm{D}^{\prime}} l_{\mathrm{BC}} \cos \left(\frac{\pi}{2}-\theta_{\mathrm{BC}^{\prime} \mathrm{D}^{\prime}}\right)\right. \\
& \left.+\left(m_{\mathrm{AB}} \frac{l_{\mathrm{AB}}}{2}-m_{\mathrm{BH}} \frac{l_{\mathrm{BH}}}{2}\right) g \cos \alpha_{1}+m_{\mathrm{AG}} g l_{\mathrm{BI}} \cos \left(\theta_{\mathrm{IBA}}-\alpha_{1}\right)\right] / l_{\mathrm{AB}}
\end{aligned}
$$

where $F_{\mathrm{C}^{\prime} \mathrm{D}^{\prime}}$ is found in Eq. (A11) and the torsional pivot reaction moments $M$ are defined in Eqs. (A13) with spring constants given in Table 2.

After the variable length $l_{\mathrm{DE}}$ is fixed, every term on the right hand side of the equation is a function of only $\alpha_{1}$. The problem is most easily solved by iteratively varying $\alpha_{1}$ until Eq. (2) equals a given thrust level. Equations (1) are used in this process to find the member deflections in the system, allowing for calculation of the moments applied by the torsional pivots.

\section{B. Displacement Sensing}

The deflection $\left|\mathbf{d}_{\mathrm{FF}^{\prime}}\right|$ was measured using a non-intrusive optical transducer, a BEI Precision Systems Linear Gap Displacement Transducer (LGDT). The LGDT uses an IR LED to illuminate the surface of the secondary beam. The 


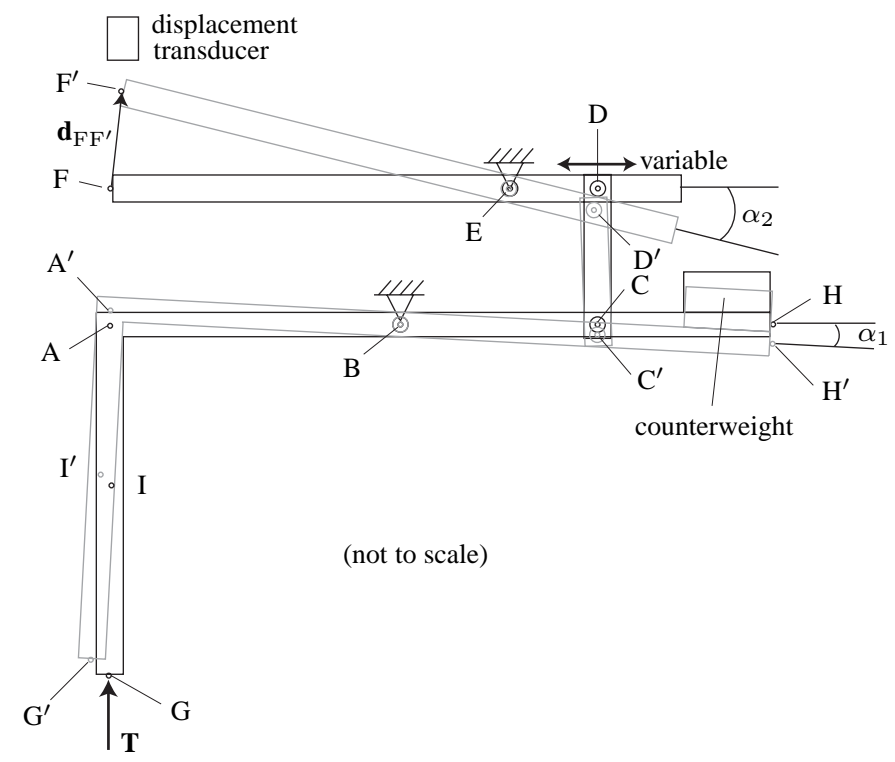

Figure 2. Schematic representation of the VTS balance mechanism components in both their undeflected and deflected positions (deflected beam positions shown in gray).

Table 1. Coordinates of the undeflected points comprising the VTS balance mechanism as shown in Fig. 2.

\begin{tabular}{c|c|c}
\hline \hline & $x(\mathrm{~cm})$ & $y(\mathrm{~cm})$ \\
\hline A & -30.5 & -5.7 \\
B & 0.0 & 0.0 \\
C & 24.1 to 28.5 & 1.9 \\
D & 24.1 to 28.5 & 17.1 \\
E & 22.9 & 17.1 \\
F & -53.3 & 18.1 \\
G & -30.5 & -158.1 \\
H & 91.4 & -5.7 \\
\hline \hline
\end{tabular}

light reflected from the target is analyzed using a ratiometric technique to derive a distance to the surface. The LGDT output is an analog voltage that increases linearly (over a given range) as the distance between the LGDT probe tip and the illuminated target increases. The conversion from the LGDT output voltage to the separation distance (over a linear response deflection range from $8.1767 \mathrm{~mm}$ to $12.9287 \mathrm{~mm}$ ) is given by

$$
d=0.4752 \mathrm{~V}+8.1767
$$

where $d$ is in millimeters. The LGDT used in the VTS has a resolution of $440 \mathrm{~nm}$ and a $1 \%$ linear range of $4.752 \mathrm{~mm}$. The sensor output is transmitted through a single twisted pair to a 16-bit A/D converter in a National Instruments SCXI data acquisition and control system. With the fine voltage resolution in the A/D conversion, the overall measurement has an error no larger than the LGDT resolution of $440 \mathrm{~nm}$. Taking this as the minimum measurable displacement of point $\mathrm{F}$ and using for this calculation $4 \mathrm{~mm}$ as an upper bound on the deflection, we can apply Eq. (2) to solve for the minimum and maximum resolvable thrust levels as a function of thruster mass and the variable length $l$ de. These predicted upper and lower bounds are shown in Fig. 3. It is readily seen that the configuration yielding the greatest displacement amplification $\left(l_{\mathrm{de}}\right.$ set to $1.3 \mathrm{~cm}$ ) allows for measurement of the minimum resolvable thrust levels while the configuration giving minimal displacement amplification $\left(l_{\text {de }}\right.$ set to $\left.5.6 \mathrm{~cm}\right)$ should be employed to measure the maximum resolvable thrust. For a $200 \mathrm{~kg}$ thruster the VTS is predicted to be capable of measuring up to $12 \mathrm{~N}$ of thrust, while the maximum measureable thrust for a $10 \mathrm{~kg}$ thruster is $800 \mathrm{mN}$. The resolution for these measurements 
Table 2. Spring constants for the torsional pivots in the VTS balance.

\begin{tabular}{c|c}
\hline \hline & Spring Constant (cm-N/rad) \\
\hline$k_{\mathrm{B}}$ & 306.5 \\
$k_{\mathrm{C}}$ & 4.21 \\
$k_{\mathrm{D}}$ & 4.21 \\
$k_{\mathrm{E}}$ & 8.42 \\
\hline \hline
\end{tabular}

(strictly based on the LGDT resolution) is roughly four orders of magnitude smaller than the maximum thrust for a particular thruster mass and linkage setting. While the VTS can presently only accommodate thrusters with a mass up to $100 \mathrm{~kg}$, using higher load-bearing flexures in the pivot of the primary beam and replacing member $\mathrm{ABCH}$ with a more robust beam that can handle greater bending loads can extend the thruster mass limit to $200 \mathrm{~kg}$.

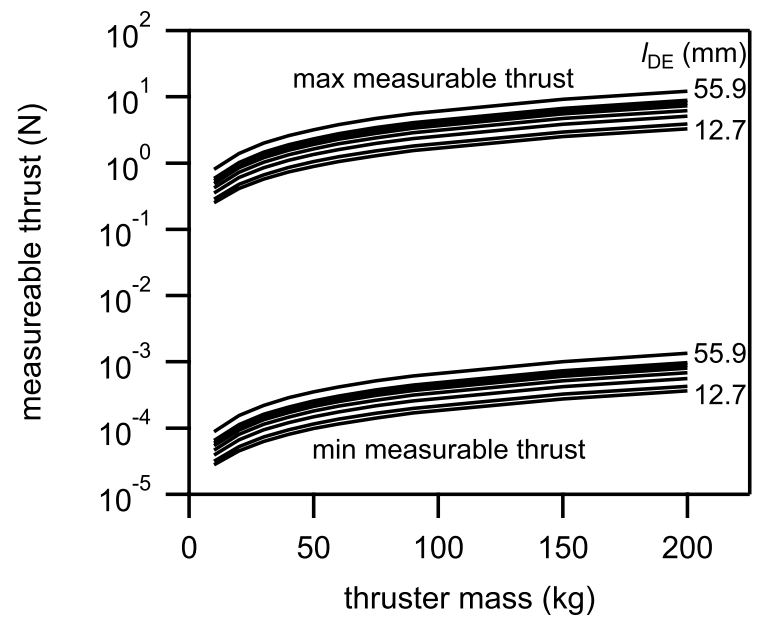

Figure 3. Minimum and maximum measurable thrust levels on the VTS as a function of thruster mass and the variable length $\mathrm{bE}_{\mathrm{E}}$. Spring constant values from Table 2 are assumed in both cases.

\section{Damping}

Damping of mechanical oscillations of the thrust balance in the VTS is achieved using a passive, eddy-current damper. This system consists of a copper plate located at the end of the secondary beam, near the displacement sensor, that passes through a magnetic field with a value of roughly 0.2 Tesla generated by rare-Earth magnets. Motion of the plate through the magnetic field generates eddy currents that dissipate mechanical energy.

\section{Level Control}

The issue of zero drift of the displacement sensor signal is primarily addressed through monitoring and control of the thrust stand position over the course of a test. Two inclinometers (Rieker NGU2U) with a 0.001 degree precision are mounted on the aluminum baseplate perpendicular to each other to allow two axis monitoring (pitch and roll). The inclinometer measurements allow for in situ monitoring of the baseplate orientation, which can change during the course of a test as the result of mechanical and/or thermally-induced deformation of the vacuum chamber to which the stand is mounted. The 2.0 inch thick aluminum plate from which the thrust stand balance mechanism (and thruster) hangs is supported at three locations, two of which are linear actuators and the third is a pure pivot point. Two highresolution stepper-motor-driven linear actuators (Ultramotion D-A.083-HT23-2-ST4/4-T6) are incorporated into the VTS, allowing for two-axis leveling control of the thrust stand. 


\section{E. Thermal Management}

A closed loop thermal management system consisting of a programmable water chiller and tubing that attaches to the sides of the 2.0 inch thick aluminum baseplate was implemented in the VTS. The thermal conditioning of the water is provided by a Thermo NESLAB HX-150 Recirculating Chiller with auxiliary heater ( $4.5 \mathrm{~kW}$ cooling capacity). The chiller can be programmed to maintain a water temperature in a user-specified range. Thermocouples allow the temperature of the thrust stand to be monitored during operation to ensure that the temperature is being maintained at a relatively constant level.

\section{F. Thruster Power Feeds}

Wires bringing power onto a thrust stand can experience Joule heating, causing them to deform during thruster operation (especially at higher current levels) and applying unbalanced forces and torques to the thrust stand. In the VTS, gallium pots are used to transfer electrical power from the rigid part of the thrust stand to the moveable balance mechanism (without the introduction of a spring constant). Because the wires on the pendulum arm are only in contact with the liquid metal in the pots, they are unable to apply time-varying loads to the thrust stand pendulum arm. This technique has been successfully demonstrated in the VAHPER thrust stand, ${ }^{4}$ and a similar, though more hazardous, method employing conductive mercury pots was used in Ref. [25].

\section{G. In-Situ Thrust Calibration}

The thrust calibration system uses a series of weights with known masses attached to a string wound onto a spool drum attached to a stepper motor. As the stepper motor unwinds the string, the masses are applied to the primary beam in the balance mechanism through a series of low-friction pulleys. The weight of the masses is transferred through this setup to the top of the primary beam at point $\mathrm{A}$. The same vertical force applied either at point A (the calibration weights) or point $\mathrm{G}$ (the thrust) will yield the same moment about point $\mathrm{B}$ and result in the same deflection at point $\mathrm{F}$. The calibration system can be operated at any time, allowing for continuous monitoring of the calibration factors.

\section{H. Data Acquisition and Control System}

The thrust stand data acquisition and control system uses 16-bit National Instruments SCXI hardware to acquire measurements from the thrust stand and to provide control commands. The system controls stepper motors that are used: for level control, for locking the position of the balance system, to perform fine adjustments to the counterweight position, and to apply/remove the calibration weights. Twelve data input channels are available for input, and they are used to sample the data from the LGDT, monitor the feedback measurements from the inclinometers, and measure the temperature readings from the various thermocouples on the thrust stand.

\section{Results of Thrust Stand Calibration}

The thrust stand assembly was calibrated in the open air while mounted on the support structure as shown in Fig. 1. Two simulated thruster masses of $26.8 \mathrm{lbm}(12.1 \mathrm{~kg})$ and $200 \mathrm{lbm}(90.7 \mathrm{~kg})$ were used in the collection of calibration data. The in situ thrust calibration system was used to apply a series of six weights to the balance. The masses of these weights are known to within $0.1 \mathrm{~g}$, with a calibration mass of $41.3 \mathrm{~g}$ used for the lighter simulated thruster and a mass of $172.2 \mathrm{~g}$ used for the heavier simulated thruster. Before a calibration sequence was performed, the thrust stand leveling sequence was initiated to ensure that the thrust stand was within $+/-0.001$ degrees of a set reference position.

The output of the LGDT is plotted as a function of time in Fig. 4a for the lighter simulated thruster and in Fig. 4b for the heavier thruster. The length $l_{\mathrm{DE}}$ for each case was $1.3 \mathrm{~cm}$. As each calibration mass is applied to the thrust stand balance, the stand rotates, yielding a stair-step shift in the output of the LGDT. The reverse situation occurs as the calibration masses are removed. The mechanism exhibits very little drift during the course of a claibration trial, effectively returning to zero displacement at the end of the calibration sequence. The repeatability of the calibration process was tested by performing three separate calibration trials for the $200 \mathrm{lbm}$ simulated thruster (Fig. 4b). The first and second calibration trials were conducted eight hours apart on one day, while the third calibration trial was conducted on the ensuing day, approximately 24 hours after the first calibration. The LGDT data from these tests exhibit excellent repeatability (less than $1 \%$ deviation between trials, with much less deviation as more weights are applied to the stand). 

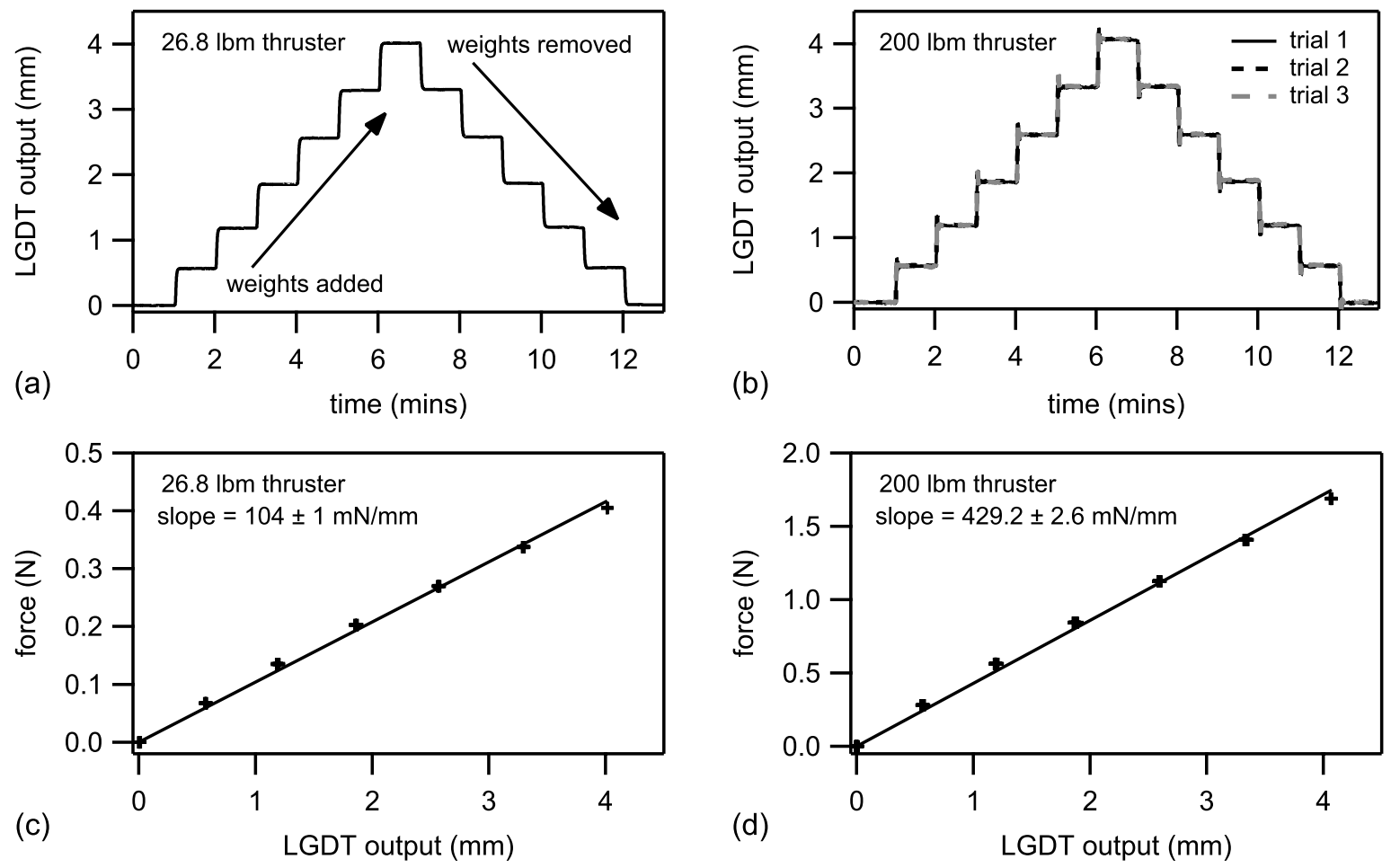

Figure 4. Time history of VTS calibration data showing LGDT measurements as calibration weights were added and removed for a simulated thruster of (a) $26.8 \mathrm{lbm}$ and (b) $200 \mathrm{lbm}$. Three trials over a span of 24 hours were performed for the latter case. Applied calibration forces and curve fits to the data plotted as a function of average LGDT response for a simulated thruster of (c) 26.8 lbm and (d) $200 \mathrm{lbm}$ (all three trials worth of data).

The applied calibration forces plotted as a function of the average LGDT response, and a resulting fit to the data set for simulated thrusters of $26.8 \mathrm{lbm}$ and $200 \mathrm{lbm}$, are plotted in Fig. 4c and d. Note that all three trials shown in Fig. $4 \mathrm{~b}$ were lumped together in one single curve fit in Fig. 4d. Given the still relatively large uncertainties in these data owing to the fact that the stand is not mounted in a vacuum chamber and is, consequently, exposed to air currents and other external disturbances, only a quick calibration analysis was performed without expending significant effort on quantifying all the errors that could propagate through the calibraiton routine. The error on the slope of each calibration curve represents only the error on the curve fit of the data, which has in past experience with the VAHPER thrust stand typically been the dominant source of error on the calibration data. The VTS thrust measurement error arising from the calibration was approximately $1 \%$ for the lighter thruster and $0.6 \%$ for the heavier thruster. The maximum force values given for each calibration run (Fig. $4 \mathrm{c}$ and d), compare favorably with the theoretical maximum measureable thrust curve given in Fig. 3.

\section{Conclusions}

We have developed a variation of a hanging pendulum thrust stand that allows for the measuring of thrust on electric propulsion devices operating in the vertical direction. An adjustable mechanical linkage system is employed to convert the thruster-induced deflection of a primary member into deflection of a secondary beam, on which measurement is performed. An adjustable counterweight is also attached to the primary beam, keeping the balance system neutrally stable. The stand is presently capable of supporting thrusters massing $100 \mathrm{~kg}$, and with minor modifications it can support testing on thrusters up to $200 \mathrm{~kg}$.

Several supporting systems have been incorporated to enhance the accuracy of the measurement. These include highly-sensitive noncontact displacement sensing, a 2-axis level monitoring and control system, an oscillation damping system, thermal control, and the delivery of power through liquid-metal pots. These subsystems serve to eliminate sources of zero drift. In addition, an in situ calibration rig enables displacement calibration at any time during a test. 
Calibration experiments were performed in open air with the test stand mounted to a support structure. Simulated thrusters possessing masses of $26.8 \mathrm{lbm}$ and $200 \mathrm{lbm}$ were used. The thrust measurement error that would arise from the calibration for the lighter thruster was $1 \mathrm{mN}$ on thrust levels of $100 \mathrm{mN}$, while those on the heavier thruster were roughly $2.5 \mathrm{mN}$ at thrust levels of $0.5 \mathrm{~N}$ and greater. Tests conducted over a timespan of 24 hours indicated minimal zero-drift.

\section{Acknowledgments}

The authors wish to thank Keith Walker and Joel Davenport of the University of Tennessee Space Institute Propulsion Laboratory for their contributions to this effort. This work was funded by the Arnold Engineering and Development Center Task Order 03-01 under contract F40 600-DO-D-0001/0024 and Task Order 06-03 under contract FA 9109-06-D-0001/0001.

\section{Appendix: Theoretical analysis of balance mechanism}

We proceed with a derivation of Eqs. 1 and 2 from first principles. Scalar quantities of the displacement vectors $\mathbf{d}_{\mathrm{ij}}$ are represented by $d_{\mathrm{ij}}$. All endpoints and vectors are the same as those defined in Fig. 2.

\section{A. Balance Mechansim Deflection Analysis}

To find the displacement amplification, we must relate the displacements $d_{\mathrm{FF}^{\prime}}$ and $d_{\mathrm{GG}^{\prime}}$. From Figs. 5a and 5b we see that isosceles triangles $\mathrm{GG}^{\prime} \mathrm{B}$ and $\mathrm{EFF}^{\prime}$ are used to write the displacements in terms of the angles $\alpha_{1}$ and $\alpha_{2}$.

$$
\begin{aligned}
\alpha_{1} & =2 \sin ^{-1}\left(\frac{d_{\mathrm{GG}^{\prime}}}{2 l_{\mathrm{GB}}}\right), \\
d_{\mathrm{FF}^{\prime}} & =2 l_{\mathrm{EF}} \sin \left(\frac{\alpha_{2}}{2}\right) .
\end{aligned}
$$

Writing an equation relating $d_{\mathrm{FF}^{\prime}}$ and $d_{\mathrm{GG}^{\prime}}$ reduces to the exercise of writing $\alpha_{2}$ in terms of $\alpha_{1}$.

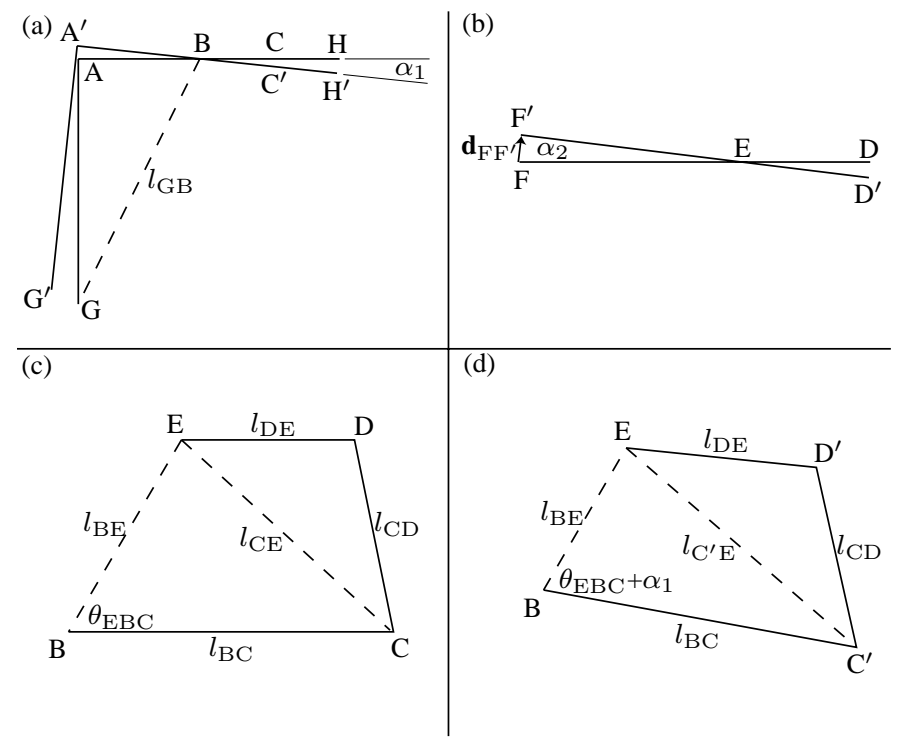

Figure 5. Schematic illustrations (not to scale) of various members in the VTS. The end points, vectors, and lengths are the same as those defined in Fig. 2

Once the length $l_{\mathrm{DE}}$ is chosen, the initial separation distances and angles within the linkage mechanism are fully known. The bulk of our analysis will focus on the quadrilateral BCDE shown in its undeflected position in Fig. 5c. 
When the mechanism is deflected as shown in Fig. 5d, we can write

$$
\begin{aligned}
& \theta_{\mathrm{EBC}^{\prime}}=\theta_{\mathrm{EBC}}+\alpha_{1}, \\
& \theta_{\mathrm{D}^{\prime} \mathrm{EB}}=\theta_{\mathrm{DEB}}-\alpha_{2} .
\end{aligned}
$$

The length $l_{\mathrm{C}^{\prime} \mathrm{E}}$ is written using the law of cosines as:

$$
l_{\mathrm{C}^{\prime} \mathrm{E}}=\left(l_{\mathrm{BC}}^{2}+l_{\mathrm{BE}}^{2}-2 l_{\mathrm{BC}} l_{\mathrm{BE}} \cos \left(\theta_{\mathrm{EBC}}+\alpha_{1}\right)\right)^{1 / 2} .
$$

With all the lengths in the triangles $\mathrm{BC}^{\prime} \mathrm{E}$ and $\mathrm{C}^{\prime} \mathrm{D}^{\prime} \mathrm{E}$ known, we again use the law of cosines to write:

$$
\begin{aligned}
\theta_{\mathrm{BC}^{\prime} \mathrm{D}^{\prime}} & =\cos ^{-1}\left(\frac{l_{\mathrm{BC}}^{2}+l_{\mathrm{C}^{\prime} \mathrm{E}}^{2}-l_{\mathrm{BE}}^{2}}{2 l_{\mathrm{BC}} l_{\mathrm{C}^{\prime} \mathrm{E}}}\right) \\
& +\cos ^{-1}\left(\frac{l_{\mathrm{C}^{\prime} \mathrm{E}}^{2}+l_{\mathrm{CD}}^{2}-l_{\mathrm{DE}}^{2}}{2 l_{\mathrm{C}^{\prime} \mathrm{E}} l_{\mathrm{CD}}}\right), \\
\theta_{\mathrm{C}^{\prime} \mathrm{D}^{\prime} \mathrm{E}} & =\cos ^{-1}\left(\frac{l_{\mathrm{DE}}^{2}+l_{\mathrm{CD}}^{2}-l_{\mathrm{C}^{\prime} \mathrm{E}}^{2}}{2 l_{\mathrm{DE}} l_{\mathrm{CD}}}\right) .
\end{aligned}
$$

The geometry is such that the angles comprising quadrilaterals $\mathrm{BCDE}$ and $\mathrm{BC}^{\prime} \mathrm{D}^{\prime} \mathrm{E}$ must both sum to $2 \pi$ radians. If we equate the angles from the two quadrilaterals, substitute for the angles in $\mathrm{BC}^{\prime} \mathrm{D}^{\prime} \mathrm{E}$ using Eqs. (A3) and (A4), and rearrange the terms, we obtain

$$
\alpha_{2}=\alpha_{1}+\theta_{\mathrm{BC}^{\prime} \mathrm{D}^{\prime}}+\theta_{\mathrm{C}^{\prime} \mathrm{D}^{\prime} \mathrm{E}}-\theta_{\mathrm{BCD}}-\theta_{\mathrm{CDE}}
$$

Given an initial geometry and selecting a value for $\alpha_{1}$, all the angles on the right-hand side of Eq. (A8) are known. Equations (A1), (A2) and (A8) allow us to relate $d_{\mathrm{GG}^{\prime}}$ to $d_{\mathrm{FF}^{\prime}}$ and are exactly those given as Eqs. (1).

\section{B. Linkage Response to Applied Thrust}

An operating thruster applies a force $\mathbf{T}$ to the thrust stand, deflecting the linkages to a new position denoted by primes (') in Fig. 2. This motion is opposed by the torque arising from the weight of the thruster, $m_{\mathrm{T}} \mathrm{g}$, and by the moments produced as the torsional springs flex from their neutral positions. Additional torques are applied by the counterweight, $m_{\mathrm{CW}} \mathrm{g}$, and the weights of the various members, $m_{\mathrm{ij}} \mathrm{g}$, acting through the centerpoints between the various points $\mathrm{i}$ and $\mathrm{j}$. To find the actual deflection $d_{\mathrm{GG}^{\prime}}$ we must sum the moments applied to each linkage.

Free body diagrams showing the moments applied by deflected torsional springs and external forces applying additional moments to both the upper and lower linkages are shown in Fig. 6, where point I has been introduced midway between points $\mathrm{A}$ and $\mathrm{G}$ and point $\mathrm{J}$ is located at the end of the beam containing points $\mathrm{D}, \mathrm{E}$, and $\mathrm{F}$ to simplify the notation. In the static case, summing the moments for linkage $\mathrm{G}^{\prime} \mathrm{A}^{\prime} \mathrm{BC}^{\prime} \mathrm{H}^{\prime}$ about point $\mathrm{B}$ yields

$$
\begin{aligned}
M_{\mathrm{B}} & +M_{\mathrm{C}^{\prime}}+m_{\mathrm{T}} g l_{\mathrm{BG}} \cos \left(\theta_{\mathrm{GBA}}-\alpha_{1}\right)-T l_{\mathrm{AB}}-m_{\mathrm{CW}} g l_{\mathrm{BH}} \cos \alpha_{1} \\
& +F_{\mathrm{C}^{\prime} \mathrm{D}^{\prime}} l_{\mathrm{BC}} \cos \left(\frac{\pi}{2}-\theta_{\mathrm{BC}^{\prime} \mathrm{D}^{\prime}}\right)+\left(m_{\mathrm{AB}} \frac{l_{\mathrm{AB}}}{2}-m_{\mathrm{BH}} \frac{l_{\mathrm{BH}}}{2}\right) g \cos \alpha_{1} \\
& +m_{\mathrm{AG}} g l_{\mathrm{BI}} \cos \left(\theta_{\mathrm{IBA}}-\alpha_{1}\right)=0,
\end{aligned}
$$

while doing the same for linkage $\mathrm{D}^{\prime} \mathrm{EF}^{\prime}$ gives

$$
\begin{aligned}
M_{\mathrm{E}} & +M_{\mathrm{D}^{\prime}}-F_{\mathrm{C}^{\prime} \mathrm{D}^{\prime}} l_{\mathrm{DE}} \cos \left(\frac{\pi}{2}-\theta_{\mathrm{C}^{\prime} \mathrm{D}^{\prime} \mathrm{E}}\right) \\
& +\left(m_{\mathrm{EF}} \frac{l_{\mathrm{EF}}}{2}-m_{\mathrm{EJ}} \frac{l_{\mathrm{EJ}}}{2}\right) g \cos \alpha_{2}=0 .
\end{aligned}
$$

Solving Eq. (A10) for $F_{\mathrm{C}^{\prime} \mathrm{D}^{\prime}}$ yields

$$
F_{\mathrm{C}^{\prime} \mathrm{D}^{\prime}}=\left[M_{\mathrm{E}}+M_{\mathrm{D}^{\prime}}+\left(m_{\mathrm{EF}} \frac{l_{\mathrm{EF}}}{2}-m_{\mathrm{EJ}} \frac{l_{\mathrm{EJ}}}{2}\right) g \cos \alpha_{2}\right] /\left[l_{\mathrm{DE}} \cos \left(\frac{\pi}{2}-\theta_{\mathrm{C}^{\prime} \mathrm{D}^{\prime} \mathrm{E}}\right)\right]
$$


(a)
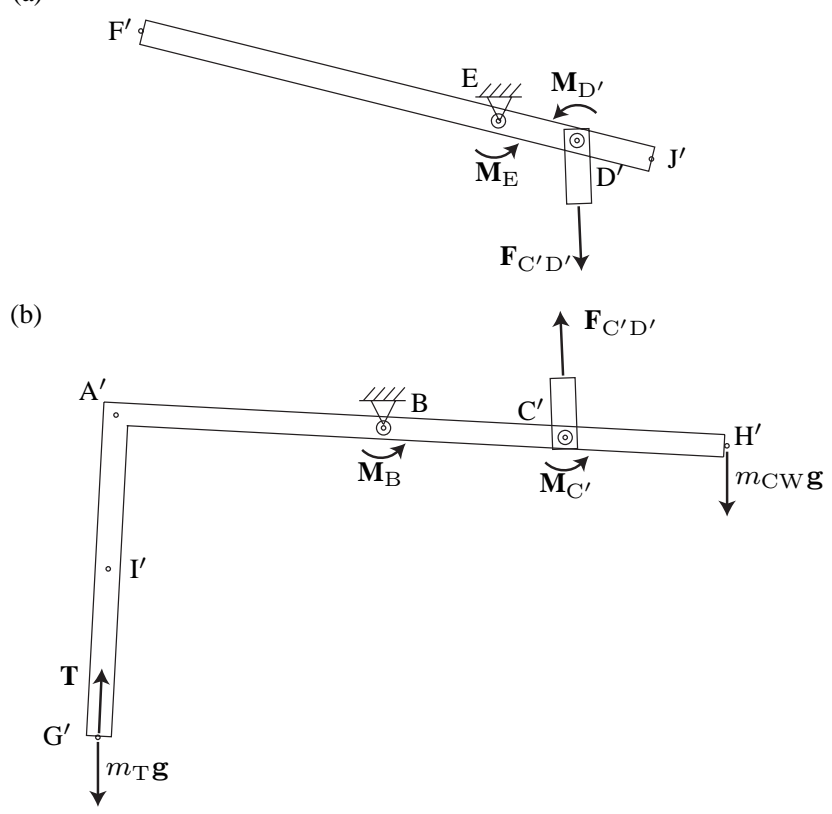

Figure 6. Free body diagrams (not to scale) showing the relevant forces and torsional spring moments applied to the (A) upper and (B) lower linkages in the VTS when the system is deflected. The deflected positions are defined in Fig. 2.

and solving Eq. (A9) for $T$ results in

$$
\begin{aligned}
T & =\left[M_{\mathrm{B}}+M_{\mathrm{C}^{\prime}}+m_{\mathrm{T}} g l_{\mathrm{BG}} \cos \left(\theta_{\mathrm{GBA}}-\alpha_{1}\right)-m_{\mathrm{CW}} g l_{\mathrm{BH}} \cos \alpha_{1}+F_{\mathrm{C}^{\prime} \mathrm{D}^{\prime}} l_{\mathrm{BC}} \cos \left(\frac{\pi}{2}-\theta_{\mathrm{BC}^{\prime} \mathrm{D}^{\prime}}\right)\right. \\
& \left.+\left(m_{\mathrm{AB}} \frac{l_{\mathrm{AB}}}{2}-m_{\mathrm{BH}} \frac{l_{\mathrm{BH}}}{2}\right) g \cos \alpha_{1}+m_{\mathrm{AG}} g l_{\mathrm{BI}} \cos \left(\theta_{\mathrm{IBA}}-\alpha_{1}\right)\right] / l_{\mathrm{AB}}
\end{aligned}
$$

which is the same equation given in Eq. (2). The moments in Eq. (A12) are

$$
\begin{array}{ll}
M_{\mathrm{B}}=\alpha_{1} k_{\mathrm{B}}, & M_{\mathrm{C}^{\prime}}=\left(\theta_{\mathrm{BC}^{\prime} \mathrm{D}^{\prime}}-\theta_{\mathrm{BCD}}\right) k_{\mathrm{C}}, \\
M_{\mathrm{E}}=\alpha_{2} k_{\mathrm{E}}, & M_{\mathrm{D}^{\prime}}=\left(\theta_{\mathrm{C}^{\prime} \mathrm{D}^{\prime} \mathrm{E}}-\theta_{\mathrm{CDE}}\right) k_{\mathrm{D}},
\end{array}
$$

where the $k$ values represent the different torsional spring constants at each position. From the deflection analysis of the previous section, all the angles in Eqs. (A12) and (A13) can be computed given an initial deflection $d_{\mathrm{GG}^{\prime}}$ (or more simply by choosing a value of $\alpha_{1}$ ).

\section{References}

${ }^{1}$ Y. Lee, G.N. Kudva, and T.A. Litzinger, "A facility for solid-propellant response measurements under pressure-driven conditions," Meas. Sci. Technol., 11, 51 (2000).

${ }^{2}$ C. Sota, Aerojet, Inc. personnal communication (2005).

${ }^{3}$ P.Y. Peterson, D.T. Jacobson, D.H. Manzella, and J.W. John, "The performance and wear characterization of a high-power, high- $\mathrm{I}_{\mathrm{p}}$ NASA Hall Thruster," 39th AIAA/ASME/SAE/ASEE Joint Propulsion Conference, Tucson, AZ, 11-14 July 2005. AIAA Paper 2005-4243.

${ }^{4}$ K.A. Polzin, T.E. Markusic, B.J. Stanojev, A. Dehoyos, and B. Spaun, "Thrust stand for electric propulsion performance evaulation," Rev. Sci. Instrum., 77, 105108 (2006).

${ }^{5}$ T.W. Haag, "Thrust stand for pulsed plasma thrusters," Rev. Sci. Instrum., 68, 2060 (1997).

${ }^{6}$ K.D. Diamant, R.B. Cohen, and J.E. Brandenburg, "High power microwave electrothermal thruster performance on water," 38th AIAA/ASME/SAE/ASEE Joint Propulsion Conference, Indianapolis, IN, 7-10 July 2002. AIAA Paper 2002-3662.

${ }^{7}$ K.D. Diamant, J.E. Brandenburg, R.B. Cohen, and J.F. Kline, "Performance measurements of a water fed microwave electrothermal thruster," 37th AIAA/ASME/SAE/ASEE Joint Propulsion Conference, Salt Lake City, UT, 8-11 July 2001. AIAA Paper 2001-3900.

${ }^{8}$ F. Paganucci, P. Rossetti, and M. Andrenucci, "Performance of an applied field MPD thruster with a preionization chamber," 33rd AIAA Plasmadynamics and Lasers Conference, Maui, HI, 20-23 May 2002. AIAA Paper 2002-2103.

${ }^{9}$ T.W. Haag, "Thrust stand for high-power electric propulsion devices," Rev. Sci. Instrum. 62, 1186 (1991). 
${ }^{10}$ L.D. Cassady, A.D. Kodys, and E.Y. Choueiri, "A thrust stand for high-power steady-state plasma thrusters," 38th AIAA/ASME/SAE/ASEE Joint Propulsion Conference, Indianapolis, IN, 7-10 July 2002. AIAA Paper 2002-4118.

${ }^{11}$ K.G. Xu and M.R. Walker, "High-power, null-type, inverted pendulum thrust stand," Rev. Sci. Instrum. 80, 055103 (2009).

${ }_{12}$ M.A. Cappelli, Q.E. Walker, and N.B. Meezan, "Performance of a linear Hall discharge with an open electron drift," 37th AIAA/ASME/SAE/ASEE Joint Propulsion Conference, Salt Lake City, UT, 8-11 July 2001. AIAA Paper 2001-3503.

${ }^{13}$ D. Manzella, R. Jankovsky, and R. Hofer, "Laboratory model $50 \mathrm{~kW}$ Hall thruster," 38th AIAA/ASME/SAE/ASEE Joint Propulsion Conference, Indianapolis, IN, 7-10 July 2002. AIAA Paper 2002-3676.

${ }^{14}$ A. Smirnov, Y. Raitses, and N.J. Fisch, "Performance studies of miniaturized cylindrical and annular Hall thrusters," 38th AIAA/ASME/SAE/ASEE Joint Propulsion Conference, Indianapolis, IN, 7-10 July 2002. AIAA Paper 2002-3823.

${ }^{15}$ E.A. Cubbin, J.K. Ziemer, E.Y. Choueiri, and R.G. Jahn, "Pulsed thrust measurements using laser interferometry," Rev. Sci. Instrum. 68, 2339 (1997).

${ }^{16}$ A. Sasoh and Y. Arakawa, "A high-resolution thrust stand for ground tests of low-thrust space propulsion devices," Rev. Sci. Instrum. 64, 719 (1993).

${ }^{17}$ A.D. Ketsdever and E.P. Muntz, "Facility effects on performance measurements of micropropulsion systems," 37th AIAA/ASME/SAE/ASEE Joint Propulsion Conference, Salt Lake City, UT, 8-11 July 2001. AIAA Paper 2001-3335.

${ }^{18}$ A.D. Ketsdever, A.A. Green, and E.P. Muntz, "Momentum flux measurements from under expanded orifices: Applications for microspacecraft systems," 39th AIAA Aerospace Sciences Meeting, Reno, NV, 8-11 Jan. 2001. AIAA Paper 2001-0502.

${ }^{19}$ B. Reed, "Decomposing solid micropropulsion nozzle performance issues," 41st AIAA Aerospace Sciences Meeting, Reno, NV, 6-9 Jan. 2003. AIAA Paper 2003-0672.

${ }^{20}$ W.D. Willis III, C.M. Zakrzwski, and S.M. Merkowitz, "Development of a thrust stand to meet LISA mission requirements," 38th AIAA/ASME/SAE/ASEE Joint Propulsion Conference, Indianapolis, IN, 7-10 July 2002. AIAA Paper 2002-3820.

${ }^{21}$ J.K. Ziemer, "Laser ablation microthruster technology," 33rd AIAA Plasmadynamics and Lasers Conference, Maui, HI, $20-23$ May 2002. AIAA Paper 2002-2153.

${ }^{22}$ T.W. Haag, "PPT thrust stand," 31st AIAA/ASME/SAE/ASEE Joint Propulsion Conference, San Diego, CA, 10-12 July 1995. AIAA Paper 95-2917.

${ }^{23}$ K.W. Stark, T. Dennis, D. McHugh, and T. Williams, "Design and development of a micropound extended range thrust stand," Technical Report No. NASA TN D-7029, Aug. 1971.

${ }^{24}$ T.E. Markusic, K.A. Polzin, E.Y. Choueiri, M. Keidar, I.D. Boyd, and N. Lepsetz, “Ablative Z-pinch pulsed plasma thruster," J. Propuls. Power 21, 392 (2005).

${ }^{25}$ H.O. Schrade, M. Auweter-Kurtz, and H.L. Kurtz, "Cathode erosion studies on MPD thrusters," 18th International Electric Propulsion Conference, Alexandria, VA, 30 Sept. - 2 Oct. 1985. AIAA Paper 85-2019. 